\title{
Review
}

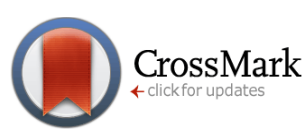

tercion

\section{Molecular basis of glaucoma and its therapeutical analysis in Pakistan: an overview}

\section{Luqman Khan ${ }^{1,2^{\star}}$, Muhammad $\mathrm{Ali}^{2}$, Muhammad Qasim ${ }^{3}$, Farhat Jabeen ${ }^{2}$, Basharat Hussain ${ }^{3}$}

*For correspondence:

luqman.zoology@gmail.com

Competing interests: The authors declare that no competing interests exist.

Received: 27 February 2017

Accepted: 20 March 2017

Published: 23 March 2017

Copyright The Author(s) 2017. This article is published with open access by BioMedPress (BMP).

This article is distributed under the terms of the Creative Commons Attribution License (CC-BY 4.0) which permits any use, distribution, and reproduction in any medium, provided the original author(s) and the source are credited.

\section{Abstract}

The human eye is an organ of vision. It plays a prime role in life, gives us the sense of sight, and enables to understand about the world around us. Visualization and interpretation of colors, shapes and dimensions of numerous objects is made possible by eye. Inherited eye diseases comprise 1/3 of all reported human genetic disorders. This review will focus on Glaucoma which comprises a predictable visual illnesses concerning optic nerve deterioration and if remains without any cure can result in failure in eyesight. The optical nerve injure comprises deterioration of the retinal ganglion cells (RGCs). Glaucoma represents a heterogeneous group of optic neuropathies with a complex genetic basis. These neuropathies gradually reduce vision without warning and often without symptoms. Different forms of glaucoma share some common clinical manifestations that usually include specific abnormal appearance of the optic nerve head, characteristic loss of visual field and chronic painless progression. Glaucoma is a progressive optical neuropathy considered by optical disc changes, nerve fiber film break, and visual field defects. Present-day treatment preferences predominantly targeting at reducing IOP by making use of pharmaceutical means, laser treatment and surgical procedure. Developed conducts target neuroprotection with vaccines, the hang-up of NO synthesis and apoptosis. Attaining a better appreciative of the pathogenesis can support in the improvement of novel handling options and, perhaps, even a remedy for glaucoma. There are more than 1.8 million glaucoma patients in Pakistan and almost half of them have already lost their eyesight, permanently, due to delay in diagnosis and treatment. About $90 \%$ population in the country has no awareness about this disease, resultantly; more and more people are becoming permanently blind in Pakistan due to untreated glaucoma. 


\section{Keywords}

Eye, glaucoma, diagnosis, treatment, Pakistan

\section{Introduction}

The term "glaucoma" covers a quantity of diverse eye disorders, all of which encompass impairment to the optic nerve (Janssen et al., 2013). One common reason is that there is too much pressure inside the eye. The situation tends to be hereditary and may not display up until later in life. The improved pressure, called intra-ocular pressure, can harm the optic nerve, which communicates images to the brain. Intra-ocular pressure is produced by a fluid termed as aqueous humor formed by the eye themselves in the compartments of the eye in the middle of the cornea and the lens (Fatt and Weissman, 2013). Generally, this liquid, called aqueous humor, runs out of the eye through a mesh-like network. If this network becomes jammed, fluid forms up, triggering glaucoma. Glaucoma typically occurs when intra-ocular pressure upsurges. This take place when the fluid stress in the eye's anterior cavity, the area in the middle of the cornea and the iris, rises.

If the aqueous humor is prevented from draining appropriately, it twitches to accumulates pressure inside the eye builds up (Gupta et al., 2014). This presses alongside the optic nerve and there is a threat that nerve cells perish. Whether the amplified intra-ocular pressure does cause loss depends on, amid other things, how well the optic nerve can struggle this pressure. Glaucoma will cause loss of vision. Readings between 10 and $21 \mathrm{~mm} \mathrm{Hg}$ are considered normal. Someone who has glaucoma does not always have above-average intra-ocular pressure.

Glaucoma sufferings roughly 70 million people around the globe, of whom around $10 \%$ are supposed to be bilaterally unsighted (Lawrence, 2014). Estimation that is put forward in 2010 nearly 60.5 million individuals were affected by glaucoma and around 8.4 million were visionless from the sickness and it is expected that by the year 2020, this amount would rise to nearby 79.6 million. Statistics gather round by the World Health Organization (WHO) indicated that glaucoma is the second foremost reason of blindness worldwide, after cataract (Bourne et al., 2016). It is expected that glaucoma affects 12 million individuals accounting for $12.8 \%$ of the republics blindness and by 2020 ; this is estimated to be 16 million. Glaucoma is accountable for $10 \%$ of blindness worldwide. Glaucoma denotes to a group of disorders categorized by distinctive variations to the retinal nerve fiber layer and optical nerve head ensuing in compact optical field compassion. Its massive social and cost-effective impact 
can be cherished by the fact that it leftovers a principal cause of sightlessness around the globe (Quigley and Broman, 2006). Glaucoma is a progressive optical neuropathy considered by optical disc changes, nerve fiber film break, and visual field defects (Pascolini et al., 2009; Resnikoff et al., 2004). This situation is known as glaucomatous optic neuropathy (GON) causing failure of visual field and ultimately to a state of irretrievable blindness (Alguire, 1990; Quigley, 1996). Glaucoma is the second principal reason of permanent blindness worldwide, thinking to influence 60 million inhabitants (Kelliher et al., 2006; Quigley and Broman, 2006). A convincing 70 million citizens suffer from glaucoma, and Asian ethnic minorities are extra susceptible to this visual ailment (Zhong et al., 2012). Linkage examinations have recognized 23 loci (the GLC1A, .GLC1L, the GLC3A-GLC3B, 2p14, 2q33.-q34, 5q22.1-q32, 10p12-p13, 14q11, 14q21-q22, 17p13, 17q25, and 19q12-q14) (Gemenetzi et al., 2012; Stone et al., 1997) for dissimilar kinds of glaucoma. Conversely, merely 4 genes (MYOC/TIGR, CYP1B1, optineurin [OPTN], and WD recap domain 36 (WDR36) (Monemi et al., 2005) have been recognized so far.

Currently, the only confirmed treatment for glaucoma is to reduce intra-ocular stress (IOP) with the aim of preventing supplementary glaucomatous optic nerve smash up (Heijl et al., 2002). Whilst many patients can be controlled with medications, patient devotion and optical toxicity are key issues in the residential globe, and lifetime outlay and ease of access to medications are issues in growing regions (Lemij et al., 2015).

Glaucoma is a composite peculiarity, in utmost condition have not pursue a straightforward heritage shape, and has inconsistent penetrance, subtle advancement, and habitually a later on commencement. Linkage examination have recognized 23 loci (the GLC1A, GLC1L, the GLC3A-GLC3B, 2p14, 2q33q34, 5q22.1-q32, 10p12-p13, 14q11, 14q21-q22, 17p13, 17q25, and 19q12q14) (Gemenetzi et al., 2012; Stone et al., 1997) for dissimilar kinds of glaucoma. Conversely, merely 4 genes (MYOC/TIGR, CYP1B1, optineurin [OPTN], and WD recap domain 36 (WDR36) (Monemi et al., 2005) have been recognized so far.

\section{Classification of Glaucoma}

Glaucoma is categorized conferring for the cause (primary VS secondary), composition of the frontal compartment (open angle VS closed angle) and stage of beginning (juvenile VS adult) (Sarfarazi, 1997). Glaucoma can categorized as primary once it happen with not any identified etiology or secondary wherever an earlier damage or illness is contributing. In broad-spectrum, glaucoma can be classified into 3 main kinds: 


\section{Primary open-angle glaucoma (POAG)}

"Open-angle" means that the angle where the iris meets the cornea is as wide and open as it should be. It is also called chronic glaucoma and is the most common form, accounting for at least $90 \%$ of all glaucoma cases. The most general type of glaucoma is primary open angle glaucoma (POAG), disturbing over 33 million persons wide-reaching (Quigley, 1996). It is produced by the slow impediment of the drainage channels, causing in improved eye pressure. Primary open-angle glaucoma (POAG), in which the iridocorneal angle and frontal eye organizations emerge ordinary in gonioscopy inspection. It is the supreme ordinary form analyzed in all populaces investigated and is particularly predominant ( 4.2\%) in individuals with African lineage. Genetic line of attack make to know that primary open angle glaucoma may be innate either as a general, multifaceted trait with fully developed onset or, fewer commonly, as a conventional Mendelian or monogenic sickness that inclines to have an premature onset (Wiggs, 2007). Hereditary link studies of complex relations, frequently of European lineage, have acknowledged at smallest amount twenty one loci (GLC) for Mendelian arrangements of POAG (Fan and Wiggs, 2010).

Juvenile onset of open angle glaucoma (JOAG) is an alternative of primary open angle glaucoma (POAG). JOAG is diagnosed prior before the age of 40 and universally described as an artifact of autosomal dominant inheritance (Alward et al., 1998). The manner of inheritance in POAG is inconclusive (Nemesure et al., 2001). Furthermore, greater than 90 point alterations have been recognized universally in numerous racial groups. These kinds of mutations report for three to five percent of POAG cases and a higher percentage of Juvenile-onset of open angle glaucoma cases (just about six to thirty six \%) (Challa, 2008; Gemenetzi et al., 2012). Primary open angle glaucoma (44.7 million cases widereaching) is measured more communal than primary angle closure glaucoma (15.7 million).

\section{Primary Congenital Glaucoma (PCG)}

Primary congenital glaucoma (PCG) is the supreme recurrent babyhood glaucoma and can lead to sightlessness during neonatal or early infantile period. Primary congenital glaucoma is the common term used for a glaucoma diagnosed in infancy or early childhood and is caused by abnormal intra-ocular fluid drainage from the eye as a result of a blocked or defective trabecular meshwork (the mesh- like drainage canals in the eye) (Ghate and Wang, 2015). It may also be due to a hereditary defect or abnormal development during pregnancy. In other cases, an abnormal drainage system may be the result of some other disease in the eye which results in secondary glaucoma. In these cases, the glaucoma may be associated with recognizable iris (the colored part of the eye), corneal, or other eye problems. Molecular genetic studies conducted during the last numerous years have established that PCG is an autosomal recessive trait. At present, four chromosomal loci have been concerned in PCG on GLC3A harboring the cytochrome P4501B1 (CYP1B1) 
gene (Stoilov et al., 1997). Congenital glaucoma is a type of blinding eye illness that ruthlessly affects the improvement of visual acuity amongst children, infants and teenagers. It is caused by the hindrance of the aqueous outflow by the maldevelopment of the frontal chamber angle and the trabecular meshwork of the eye for the period of the embryonic development phase (Maul et al., 1980). PC Glaucoma is autosomal recessive eye disarray observed in intermittent and familial cases. The Primary Congenital Glaucoma is universal in North Africa and at hand in a more harsh form than in the western world (Helmy, 2016). The pervasiveness of pediatric glaucoma in the Middle East is 1:2500, while in consanguineous Slovakian children, it is 1out of 1250 . The incidence ranges between 1out of 10,000 to 1out of 12,500 in western countries (Helmy, 2016).

The popularity of Primary congenital glaucoma differs permitting to the topographical position and civilization. The occurrence is 1/10,000 in Western motherlands, 1 out of 2,500 in Arabic people, and uppermost in the Gypsy inhabitants of Slovakia, wherever its prevalence is 1 in every 1,250 living births outstanding to an elevation speed of cousin marriages in these republics (Bejjani et al., 2000; Sarfarazi et al., 2003). The predominance of Primary congenital glaucoma in south Indian is estimated to be 1 in 3,300 and result 4.2 percent of infancy loss of sight (Dandona et al., 1998). 3 loci have been recognized: the GLC3A (2p21) (Sarfarazi et al., 1995), the GLC3B (1p36) (Akarsu et al., 1996) and GLC3C (14q24.3) (Stoilov et al., 2002).

\section{Primary angle Closure Glaucoma (PACG)}

It is caused by clogged drainage channels, causing in a sudden increase in intraocular pressure 12-21. It is also called acute glaucoma or narrow-angle glaucoma. Unlike open-angle glaucoma, angle-closure glaucoma is a result of the angle between the iris and cornea closing. It is relatively a less common form of glaucoma. Primary angle closure glaucoma (PACG) is the supreme widespread type of glaucoma universally (Kuehn et al., 2011). Nevertheless, primary angle closure glaucoma (PACG) is thought to be the most familiar reason of bilateral glaucoma sightlessness cosmopolitantly (Quigley et al., 2001). This is a sub kind of glaucoma, and can be defined as an anatomic disarray of the frontal cavity, through which the drainage position is obstructed by the frontal development of the iris (Lin et al., 1997). Primary angle closure glaucoma leftovers a main reason of unalterable blindness, predominantly in Asian countries such as China (Foster et al., 2000), Mongolia (Foster et al., 1996), Singapore (Foster et al., 2000), and India (Dandona et al., 2000) with up to $80 \%$ of the predictable 15 million citizens afflicted with PACG inhabitant in Asia (Quigley and Broman, 2006). The figure of patients with PACG is probable to rise by roughly 5 million people from 16 million over the next decade (Quigley and Broman, 2006). Quite a lot of anatomic hazard issues for the improvement of Primary angle closure glaucoma has been famous together with a narrow frontal chamber deepness and petite axial distance. Pretended replica organizations have providing the facts that the occurrence of equally amplified lens curving and a undersized zonule-iris space add to a pupil block in angle closure glaucoma (Huang and Barocas, 2004). 
PACG patients have been found to have exacting anatomic biometric skin tone together with shallow anterior chambers (Lin et al., 1997), lens breadth and position (Foster et al., 1996), constricted iridio-trabecular drainage angles, dumpy axial lengths (Abu-Amero et al., 2007), and hyperopic refractive fault (Congdon et al., 1996). The infection is accompanying with grownup stage, womanly masculinity and rivalry (anterior compartment angle is thinner in Eskimos and Asians (Salmon, 1999).

Numerous studies have exposed that genetic factors take part in an chief role in the development of PACG (Alsbirk, 1975; Amerasinghe et al., 2011). Although a sum of susceptible loci and genetic factor have been investigated for PACG, the accurate genes underlying PACG have not been recognized (Cong et al., 2009).

\section{Most frequently glaucoma genes reported in Pakistan}

Novel CYP1B1 mutations in consanguineous Pakistani families with primary congenital glaucoma identified an innovative cyp1b1 mutation in consanguineous Pakistani families with primary congenital glaucoma. The disease-causing alterations could be identified in $~ 31 \%$ of PCG affected families from Pakistani population (Firasat et al., 2008). This frequency estimation of CYP1B1 mutations in our population may be imprecise because of a small number of PCG families studied. Nonetheless, it connotes the prominence of CYP1B1 in PCG pathogenesis. Homozygosity mapping in consanguineous Pakistani family revealed one 11-Mb homozygous area incorporating the CYP1B1 gene (Micheal et al., 2015b). A homozygous CYP1B1 missense mutation (p. Arg390His) was recognized in this family. Sequence analysis of CYP1B1 in 39 supplementary families revealed one known and three fresh homozygous mutations in PCG (p.Ala288Pro, p.Asp242Ala, p.Arg355* and p.Arg290Profs*37). In POAG, one novel heterozygous missense mutation (p.Asp316Val) was recognized in one family and a beforehand reported mutation (p.Glu229Lys) was identified in three families. CYP1B1 mutations are the prime cause of primary congenital glaucoma in Pakistani patients (Rauf et al., 2016). Also recounted a family from Pakistan in which participants have inherited JOAG and PCG due to a known homozygous mutation in CYP1B1 (Bashir et al., 2015).

LTBP2 is the succeeding gene concerned in PCG to date. identification of homozygous null mutations in LTBP2 as a basis of PCG in human patients (Khan, 2011). These results might have insinuations for the clinical supervision of infancy sightlessness and give new intuitions into the development of the anterior organizations of the eye, implying that LTBP2 may have an critical structural role in keeping the shape of the ciliary body and its neighboring structures.

Another homozygous null mutation in LTBP2 as a trigger of PCG reported in Pakistani as well as Gypsy patients (Ali et al., 2009). Micheal et al., 
(2015) revealed that variants in ASB10 were found to be significantly associated with sporadic POAG in the Pakistani population (Micheal et al., 2015a).

First described MYOC correlated glaucoma from Pakistan isolating as autosomal dominant peculiarity in large family detected with JOAG (Waryah et al., 2013). Identification of innovative disease producing allele in MYOC suggests hereditary heterogeneity of the populace. Association of novel disarray allele indicates genetic heterogeneity of the populace. Linkage scrutiny revealed an autosomal dominant allele at GLC1A1 locus, co-segregating with disorder phenotype in a huge consanguineous household, enrolled from inner of Sindh area. Succeeding sequencing of MYOC gene in all patients, recognized a heterozygous c.1130 CNG variation in exon 3, substituting Threonine to Arginine at codon 377 of Myocilin. Preponderance of MYOC mutations (97\%) has been discovered in exon 3 of the gene, which code a functionally essential Olfactomedin domain. The data indicate that Threonine residue at 377 codon of MYOC is functionally essential and its changeover with Arginine bases hardhitting form of glaucoma.

\section{Present-Day Treatment Preferences in Pakistan}

Glaucoma is a lineage of chronic disorders due to the worsening of the optic nerve; its onset is asymptomatic in early phases and leads to sightlessness if left untouched. It is the next supreme usual cause of blindness globally with an predictable worldwide occurrence of about 67 million (Consoli and Ramlogan, 2015). The causes behindhand glaucoma and the manner in which it spearheads to loss of eyesight have not been clearly acknowledged; glaucomatous loss can be decelerated down but not reversed, and no particular precautionary measures exist. To date the maximum important regions of enhancements distresses the cataloguing of different forms have the disorder as well as cleansing clinically and pharmacological involvements for very specific conclusions. Glaucoma creates a thought-provoking case analysis in that the obstinacy of a specific framing which is now solidly considered by the ophthalmology medical society as only somewhat correct at source of much misdiagnosis and fairly unsuccessful clinical reaction.

The objective of remedying glaucoma lies predominantly on checking or postponing the loss of optical field (Brubaker, 2003). Since neuronal cell fatality is irretrievable, no treatment exists once the visual field is disappeared. Though, since IOP is the principal risk source causing the loss of RGCs, the approaches of handling mostly involve lessening IOP (Brubaker, 2003). Other essential factors such as cost, suitability and well-being should also be measured (Fechtner and Realini, 2004). Undercurrent treatments for glaucoma involve medication, laser usage and operation. 
With early analysis and appropriate medication and cure, glaucoma can be controlled. Conversely, sight loss causing from glaucoma cannot be renovated. At the present-day, there is no remedy. Once perceived, glaucoma usually needs continuing, long-standing care.

But beforehand the cure recognizing is important. Diagnosing glaucoma is not continually stress-free. The most principal anxiety is defending eyesight. Physician aspects at many aspects before making decisions about treatment.

\section{Glaucoma Diagnosing}

\section{Tonometry}

In tonometry, eye drops are used to emotionless the eye. Afterward a physician or technician uses a stratagem called a tonometer to measure the inner stress of the eye.A small aggregate of pressure is pertained to the eye by a minute device. The normal range for eye pressure is $12-22 \mathrm{~mm} \mathrm{Hg}$. The level of eye pressure by which glaucoma progresses is not the same for everybody and some individuals can get glaucoma even if their pressures are in the normal range.

\section{Ophthalmoscopy}

This investigative route aids the doctor scrutinize optic nerve for glaucoma impairment. Eye drops are used to expand the pupil so that the physician sees throughout eye with a particular lens in direction to observe the form and color of the optic nerve.

\section{Perimetry}

Perimetry (or a ophthalmic field assessment) creates a map of field of visualization. This analysis helps a specialist to regulate whether a individual vision has been disturbed by glaucoma.

\section{Gonioscopy}

This is a investigative exam that supports to regulate whether the position wherever the iris gathers the cornea is open, thin, or closed. Through the examination, eye droplets are used to distress the eye and a distinct hand-held contact lens is smoothly positioned on the eye for a few minutes.

\section{Pachymetry}

It measures the wideness of the cornea, the well-defined opening at the anterior of the eye. Corneal thickness has likely to effect eye pressure interpretations. Uncertainty a cornea is thicker than normal, pressure evaluations with a 
tonometer may be sophisticated. This contributes your eye physician surplus evidence for glaucoma analysis.

\section{Medications}

Glaucoma is characteristically cured with the use of medications that either helps the unsolidified drain healthier or lessening the quantity of fluid built by the eye. In Most incidents, prescription can securely control eye pressure for several years.

Medications encompass hindering the incursion of aqueous humor, improving the outlay of aqueous humor, shielding the optical nerves (Woodward and Gil, 2004) and biasing the osmotic pressure concerning plasma and the eyes (Kwon et al., 2009). $\alpha 2$ adrenoreceptor agonists and $\beta 1$ receptor antagonists depress IOP by impeding the inflow of aqueous humor to the eye. Timolol, which is the supreme recommended drug, and betaxolol, which has the littlest universal side effects, are together $\beta 1$ receptor blockers (Woodward and Gil, 2004). A third kind of drug that restrains the inflow of humor is carbonic anhydrase inhibitors, such as acetazolamide and dorzolamide. Such medications are regularly prepared jointly as in Cosopt (dorzolamide hydrochloride and Timolol maleate) (Fechtner and Realini, 2004). Alternative approach of decreasing IOP is by boosting the outflow of humor from the eyes over the use of muscarinic acetylcholine receptor agonists (Schwartz and Budenz, 2004; Woodward and Gil, 2004). This method is unintended, but encompasses a muscarinic acetylcholine receptor (M3)-mediated narrowing of the ciliary muscle (Woodward and Gil, 2004). The shrinkage triggers the broadening of the gaps in the trabecular meshwork. The latest class of drugs using this approach is the prostaglandin F2 $\alpha$ byproducts which boost the uveoscleral outflow (Khaw et al., 2004). Bimatoprost falls underneath this classification and is considered the furthermost successful anti-glaucoma drug (Woodward and Gil, 2004).

\section{Laser and Operation}

A subordinate choice for cure of glaucoma is the use of laser treatment. The principal scheme encompasses "burning" holes in several spaces inside the eyes incorporating the ciliary and the pigmented trabecular meshwork cells (Schwartz and Budenz, 2004). The profits contain being noninvasive, demanding fewer patient observance and decreasing the likelihood of infectivity or hemorrhage. The IOP of most patients can cutback approximately 20-30\%, but the treatment result wears off 5-10\% each year. In addition with timolol, the two year IOP decreasing attainment ratio is $70 \%$, likened with the laser isolated (44\%) and timolol alone (30\%) (Schwartz and Budenz, 2004). 
A everyday practice of operation is trabeculectomy, which generates a secured channel permitting aqueous humor to run from the fore chamber inside the eye to sub-Tenon's and sub conjunctival area (Khaw et al., 2004; Schwartz and Budenz, 2004). The benefits of operation involve alleviating IOP and avoiding the necessities for exacting patient passivity and constant drug expenditures (Schwartz and Budenz, 2004). Surgery is well-thought-out as the last remedy as failure of operation can outcome in instantaneous blindness due to impediments such as choroidal outflow, hypotonic maculopathy, suprachoroidal bleeding and optical nerve dowsing (Schwartz and Budenz, 2004).

\section{Alternative Surgical Treatments}

Looking for to moderate difficulties accompanying with established glaucoma operation, alternate surgical possibilities have been established.

- The Ex-Press tiny glaucoma shunt is used with established trabeculectomy methods to systematize the procedure and conceivably decrease the possibilities of the eye pressure becoming excessively low in the immediate post-operative stage, which is infrequently a problematic with established methodologies.

- Canaloplasty is a technique that implicates magnifying the surviving fluid outflows passageway (the Schlemm's canal) in supplement to generating a novel fluid outflow alleyway within the eye wall.

\section{Gentler sorts of laser Cyclophotocoagulation}

These innovative methodologies to glaucoma operation show potential for improved protection. As with all novel practices, time and continuation conclusions are compulsory to see which medical measures will persist advantageous for relieving glaucoma patients durable.

\section{Forthcoming Treatment Possibilities for treatment of glaucoma in Pakistan}

Based on latest information gotten from research on the pathology of neuronal apoptosis, there are numerous practices of new treatments that can be helpful for diagnosis of glaucoma in Pakistani population. Some of them are discussed here.

\section{Minimally Invasive Glaucoma Surgery (MIGS)}

In this technique, contrasting conventional glaucoma operation, there is minimum maneuvering of the sclera and the conjunctiva. Whilst these practices 
lessen the frequency of hitches, some quantity of efficacy is also transacted for the better protection.

- Miniaturized forms of trabeculectomy; operating tiny, microscopic sized ducts that can be injected into the eye and trench fluid from the internal of the eye to beneath the conjunctiva, these innovative procedures are aimed to create the trabeculectomy process securer.

- Complete internal or suprachoroidal shunts; by Using teeny tubes with very slight internal openings, the front of the eye is connected to the suprachoroidal space between the retina and the wall of the eye to intensify the drainage of fluid from the eye.

- Trabecular Operation; the trabecular meshwork can be detached or evaded.

\section{Neuro defensive Vaccines}

Subsequently resistance to elevated intra ocular Pressure is immune related, Tcell provoked neuro-protection may immunize the retinal ganglion cells from apoptosis. For instance, copolymer-1 could be used as a vaccine as it is an antigen that cross responds with a widespread array of T-cells, and can provoke a defensive immune reaction to shield retinal ganglion cells from cell mortality initiated by toxins or improved Intra ocular Pressure (Bakalash et al., 2003). A fundamental concern for planning neuro-defensive vaccines is the position of protection. Some recommended that the focus should be in the retinal ganglion cells and not in the optical nerves because in the initial glaucomatous phase cell fatality stimulated by higher intra ocular pressure that arises in the retinal ganglion cells, not in the optical nerve (Bakalash et al., 2003). R16, a peptide derivative from the retinal ganglion cell, is one paradigm of a neuro-protecting vaccine. Though R16 can instigate slight retinal ganglion cell death for those deprived of glaucoma, the advantage from this treatment extremely surpassed the mutilation from untreated glaucoma situations (Bakalash et al., 2003).

\section{NMDA Receptor Antagonists}

Memantine is a NMDA receptor opponent that chunks unnecessary NMDA receptor action. This medication has been accepted for medical use in Europe for the healing of Alzheimer's disease and vascular dementia, although its efficiency in preventing glaucomatous retinal ganglion cell disintegration is still undetermined (Lipton, 2003).

\section{INOS-2 Inhibitors}

Subsequently the up regulation of iNOS-2 is injurious to neurons, its inhibition could have a neuro-defensive outcome. An inhibitor like amino guanidine can inhibit the mortality of around $75 \%$ of retinal ganglion cells during six months of 
provoked higher intra ocular pressure and help to prevent additional damage of retinal ganglion cells (Neufeld, 2004).

\section{Nutritive Complements}

A thought-provoking alternate to amino guanidine is Ginkgo biloba extract (EGb 761). Ginkgo biloba is used as a nourishing complement for the decline of platelet accumulation, vasodilation and lessening of blood viscidness (Bartlett and Eperjesi, 2004). This comprises 24 percent flavonoid glycosides and 6 percent terpenoids, which might prevent toxicity and NO free radical accretion by impeding iNOS (Hirooka et al., 2004). In experimentations when intra ocular pressure is raised in rats by cautery of episcleral vessels, nurturing the rats $30 \mathrm{mg}$ of EGb 761/day for about five months reduced retinal ganglion cell damage from $29.9 \%$ to $4.6 \%$ (Hirooka et al., 2004). Additional research scrutinizing the alteration of $\mathrm{NO}$ in reaction to EGb 761 treatment might deliver insight into its neuro-defensive method.

\section{Calcium Channel Blockers}

Utmost apoptotic means comprise increasing intracellular calcium stages. Flunarizine, a calcium network blocker, has been indicated to expressively increase retinal ganglion cells existence in rat and rabbit mockups by decreasing intra ocular pressure (Osborne et al., 2002). Nevertheless, the accurate method of this and further calcium channel blockers desires to be explained.

\section{STAT-3 Initiation}

Alternative objective is the signal transducers and activators of transcription protein 3 (STAT-3). They play an significant role in cell development and discrimination and are of significance due to the messenger RNA of this protein is upbeat regulated in rats with glaucoma (Thanos and Naskar, 2004). The initiation of STAT-3 passageway could impede apoptosis by suppressing caspase-3. One molecule that has been examined is ciliary neurotropic factor (CNTF), which is an interleukin-6 cytokine. The insertion of CNTF into rat eyes with enlarged intra ocular pressure decreases apoptosis, phosphorylates STAT-3, and downgrades the action of caspase-3 (Adamus et al., 2003). Interleukin-10 also has neuro protecting action through the STAT-3 passageway (Boyd et al., 2003).

\section{Caspase Inhibitors}

Inhibitors of apoptosis protein (IAP) can correspondingly decrease apoptosis by impeding Caspase. Baculoviral IAP repeat-containing protein-4 (BIRC-4) is a direct inhibitor of Caspase 3, 7 and 9. BIRC-4, transducted into the eye, can obstruct apoptosis of optical nerve axons (McKinnon et al., 2002). A pharmacological methodology for apoptosis inhibition is the usage of minocycline, which could inhibit caspase-3-induced apoptosis (Baptiste et al., 
2004). It proliferate the persistence rate of retinal ganglion cells visible to the damaging results of glutamate. Moreover, it can act synergistically with MK-801, an opponent to NMDA receptors, to escalate retinal ganglion cells existence percentage.

\title{
Heat Shock Proteins
}

Geranylgeranylacetone (GGA) is an acyclic polyisoprenoid presently used in Japan as an anti-ulcer remedy. The neuro defensive effects of the medication are accelerated through the use of heat shock proteins. Specifically, Heat Shock Protein 72 looks to act as an opposing apoptotic chaperone protein that inhibits with various phases in the apoptotic passageway. Systematically, the drug is assumed to stimulate Heat Shock Factor 1 (HSF-1), a transcription element for heat shock protein, which oligomerizes in the cytosol and transfer into the nucleus once visible to stressors (Sohn et al., 2013).

\section{CONCLUSION}

There is no medication for glaucoma still, and vision loss is irretrievable, consequently molecular diagnostics for predictive assessment and early interference is essential to decrease the influence of visual mutilation and eventually blindness. To accomplish this goal, the requirement is to exemplify all subtypes of glaucoma at molecular level and recognize loci/genes contributing to this ophthalmic disorder in diverse populaces.

\section{Abbreviations}

\author{
PCG: Primary Congenital glaucoma \\ POAG: Primary Open Angle Glaucoma \\ PACG: Primary angle Closure Glaucoma \\ RGCs: Retinal ganglion cells \\ IOP: Intra Ocular Pressure \\ CYP1B: Cytochrome P450 1B1 \\ LTBP2: Latent Transforming Growth Factor-Beta-Binding Protein 2
}

\section{Author Contribution}

LK collected data and wrote the manuscript. MA, MQ participated in the design and editing of the manuscript. FJ, and BH edited the first draft. 


\section{References}

Abu-Amero, K.K., Morales, J., Osman, M.N., and Bosley, T.M. (2007). Nuclear and mitochondrial analysis of patients with primary angle-closure glaucoma. Investigative ophthalmology \& visual science 48, 5591-5596.

Adamus, G., Sugden, B., Shiraga, S., Timmers, A.M., and Hauswirth, W.W. (2003). Antiapoptotic effects of CNTF gene transfer on photoreceptor degeneration in experimental antibody-induced retinopathy. Journal of autoimmunity 21, 121-129.

Akarsu, A.N., Turacli, M.E., Aktan, S.G., Barsoum-Homsy, M., Chevrette, L., Sayli, B.S., and Sarfarazi, M. (1996). A second locus (GLC3B) for primary congenital glaucoma (Buphthalmos) maps to the 1p36 region. Human molecular genetics 5, 1199-1203.

Alguire, P. (1990). The Eye Chapter 118 Tonometry> Basic Science. Walker HK, Hall WD, Hurst JW Clinical methods: the history, physical, and laboratory examinations.

Ali, M., McKibbin, M., Booth, A., Parry, D.A., Jain, P., Riazuddin, S.A., Hejtmancik, J.F., Khan, S.N., Firasat, S., and Shires, M. (2009). Null mutations in LTBP2 cause primary congenital glaucoma. The American Journal of Human Genetics 84, 664-671.

Alsbirk, P. (1975). ANTERIOR CHAMBER DEPTH AND PRIMARY ANGLE-CLOSURE GLAUCOMA. Acta ophthalmologica 53, 436-449.

Alward, W.L., Fingert, J.H., Coote, M.A., Johnson, A.T., Lerner, S.F., Junqua, D., Durcan, F.J., McCartney, P.J., Mackey, D.A., and Sheffield, V.C. (1998). Clinical features associated with mutations in the chromosome 1 open-angle glaucoma gene (GLC1A). New England Journal of Medicine 338, 1022-1027.

Amerasinghe, N., Zhang, J., Thalamuthu, A., He, M., Vithana, E.N., Viswanathan, A., Wong, T.Y., Foster, P.J., and Aung, T. (2011). The heritability and sibling risk of angle closure in Asians. Ophthalmology 118, 480-485.

Bakalash, S., Kessler, A., Mizrahi, T., Nussenblatt, R., and Schwartz, M. (2003). Antigenic specificity of immunoprotective therapeutic vaccination for glaucoma. Investigative ophthalmology \& visual science 44, 3374-3381.

Baptiste, D.C., Hartwick, A.T., Jollimore, C.A., Baldridge, W.H., Seigel, G.M., and Kelly, M.E. (2004). An investigation of the neuroprotective effects of tetracycline derivatives in experimental models of retinal cell death. Molecular pharmacology 66, 1113-1122.

Bartlett, H., and Eperjesi, F. (2004). An ideal ocular nutritional supplement? Ophthalmic and Physiological Optics 24, 339-349.

Bashir, R., Tahir, H., Yousaf, K., Naz, S., and Naz, S. (2015). Homozygous p. G61E mutation in a consanguineous Pakistani family with co-existence of juvenile-onset open angle glaucoma and primary congenital glaucoma. Gene 570, 295-298.

Bejjani, B.A., Stockton, D.W., Lewis, R.A., Tomey, K.F., Dueker, D.K., Jabak, M., Astle, W.F., and Lupski, J.R. (2000). Multiple CYP1B1 mutations and incomplete penetrance in an inbred population segregating primary congenital glaucoma suggest frequent de novo events and a dominant modifier locus. Human molecular genetics 9, 367-374.

Bourne, R.R., Taylor, H.R., Flaxman, S.R., Keeffe, J., Leasher, J., Naidoo, K., Pesudovs, K., White, R.A., Wong, T.Y., and Resnikoff, S. (2016). Number of People Blind or Visually Impaired by Glaucoma Worldwide and in World Regions 1990-2010: A Meta-Analysis. PloS one 11, e0162229. 
Boyd, Z.S., Kriatchko, A., Yang, J., Agarwal, N., Wax, M.B., and Patil, R.V. (2003). Interleukin-10 receptor signaling through STAT-3 regulates the apoptosis of retinal ganglion cells in response to stress. Investigative ophthalmology \& visual science 44, 5206-5211.

Brubaker, R. (2003). Introduction: three targets for glaucoma management. Survey of ophthalmology $48, \mathrm{~S} 1$.

Challa, P. (2008). Glaucoma genetics. International ophthalmology clinics 48, 73.

Cong, Y., Guo, X., Liu, X., Cao, D., Jia, X., Xiao, X., Li, S., Fang, S., and Zhang, Q. (2009). Association of the single nucleotide polymorphisms in the extracellular matrix metalloprotease-9 gene with PACG in southern China.

Congdon, N.G., Quigley, H.A., Hung, P.T., Wang, T., and Ho, T. (1996). Screening techniques for angle-closure glaucoma in rural Taiwan. Acta Ophthalmologica Scandinavica 74, 113-119.

Consoli, D., and Ramlogan, R. (2015). The silent thief of sight. Medical Innovation: Science, Technology and Practice, 142.

Dandona, L., Dandona, R., Mandal, P., Srinivas, M., John, R.K., McCarty, C.A., and Rao, G.N. (2000). Angle-closure glaucoma in an urban population in southern India: the Andhra Pradesh Eye Disease Study. Ophthalmology 107, 1710-1716.

Dandona, L., Williams, J.D., Williams, B.C., and Rao, G.N. (1998). Population-based assessment of childhood blindness in southern India. Archives of ophthalmology 116, 545-546.

Fan, B.J., and Wiggs, J.L. (2010). Glaucoma: genes, phenotypes, and new directions for therapy. The Journal of clinical investigation 120, 3064-3072.

Fatt, I., and Weissman, B.A. (2013). Physiology of the eye: an introduction to the vegetative functions (Butterworth-Heinemann).

Fechtner, R.D., and Realini, T. (2004). Fixed combinations of topical glaucoma medications. Current opinion in ophthalmology 15, 132-135.

Firasat, S., Riazuddin, S., Khan, S.N., and Riazuddin, S. (2008). Novel CYP1B1 mutations in consanguineous Pakistani families with primary congenital glaucoma.

Foster, P.J., Baasanhu, J., Alsbirk, P.H., Munkhbayar, D., Uranchimeg, D., and Johnson, G.J. (1996). Glaucoma in Mongolia: a population-based survey in Hövsgöl Province, northern Mongolia. Archives of ophthalmology 114, 1235-1241.

Foster, P.J., Oen, F.T., Machin, D., Ng, T.-P., Devereux, J.G., Johnson, G.J., Khaw, P.T., and Seah, S.K. (2000). The prevalence of glaucoma in Chinese residents of Singapore: a cross-sectional population survey of the Tanjong Pagar district. Archives of Ophthalmology 118, 1105-1111.

Gemenetzi, M., Yang, Y., and Lotery, A. (2012). Current concepts on primary open-angle glaucoma genetics: a contribution to disease pathophysiology and future treatment. Eye 26, 355-369.

Ghate, D., and Wang, X. (2015). Surgical interventions for primary congenital glaucoma. The Cochrane Library.

Gupta, R., Gupta, B., Kshitij, A., and Bala, A. (2014). Glaucoma Research: A Scientometric Study of Indian Publications Output, 2002-11. DESIDOC Journal of Library \& Information Technology 34. 
Heijl, A., Leske, M.C., Bengtsson, B., Hyman, L., Bengtsson, B., and Hussein, M. (2002). Reduction of intraocular pressure and glaucoma progression: results from the Early Manifest Glaucoma Trial. Archives of ophthalmology 120, 1268-1279.

Helmy, H. (2016). Combined trabeculotomy-trabeculectomy versus Ahmed valve implantation for refractory primary congenital glaucoma in Egyptian patients: a longterm follow-up. Electronic Physician 8, 1884.

Hirooka, K., Tokuda, M., Miyamoto, O., Itano, T., Baba, T., and Shiraga, F. (2004). The Ginkgo biloba extract (EGb 761) provides a neuroprotective effect on retinal ganglion cells in a rat model of chronic glaucoma. Current eye research 28, 153-157.

Huang, E.C., and Barocas, V.H. (2004). Active iris mechanics and pupillary block: steadystate analysis and comparison with anatomical risk factors. Annals of biomedical engineering 32, 1276-1285.

Janssen, S.F., Gorgels, T.G., Ramdas, W.D., Klaver, C.C., van Duijn, C.M., Jansonius, N.M., and Bergen, A.A. (2013). The vast complexity of primary open angle glaucoma: disease genes, risks, molecular mechanisms and pathobiology. Progress in retinal and eye research 37, 31-67.

Kelliher, C., Kenny, D., and O'Brien, C. (2006). Trends in blind registration in the adult population of the Republic of Ireland 1996-2003. British journal of ophthalmology 90, 367-371.

Khan, A.O. (2011). Genetics of primary glaucoma. Current opinion in ophthalmology 22, 347-355.

Khaw, P., Shah, P., and Elkington, A. (2004). Glaucoma--2: treatment. BMJ 328, 156-158.

Kuehn, M.H., Wang, K., Roos, B., Stone, E.M., Kwon, Y.H., Alward, W.L., Mullins, R.F., and Fingert, J.H. (2011). Chromosome 7q31 POAG locus: ocular expression of caveolins and lack of association with POAG in a US cohort.

Kwon, Y.H., Fingert, J.H., Kuehn, M.H., and Alward, W.L. (2009). Primary open-angle glaucoma. New England Journal of Medicine 360, 1113-1124.

Lawrence, J.M. (2014). Pattern of ocular findings among patients aged 40 years and above attending eye clinic at Juba teaching hospital in Southern Sudan (University of Nairobi).

Lemij, H.G., Hoevenaars, J.G., van der Windt, C., and Baudouin, C. (2015). Patient satisfaction with glaucoma therapy: reality or myth? Clinical ophthalmology (Auckland, NZ) 9, 785.

Lin, Y., Wang, T., and Hung, P. (1997). Biometric study of acute primary angle-closure glaucoma. Journal of the Formosan Medical Association= Taiwan yi zhi 96, 908-912.

Lipton, S.A. (2003). Possible role for memantine in protecting retinal ganglion cells from glaucomatous damage. Survey of ophthalmology 48, S38-S46.

Maul, E., Strozzi, L., Muñoz, C., and Reyes, C. (1980). The outflow pathway in congenital glaucoma. American journal of ophthalmology 89, 667-675.

McKinnon, S.J., Lehman, D.M., Tahzib, N.G., Ransom, N.L., Reitsamer, H.A., Liston, P., LaCasse, E., Li, Q., Korneluk, R.G., and Hauswirth, W.W. (2002). Baculoviral IAP repeatcontaining-4 protects optic nerve axons in a rat glaucoma model. Molecular Therapy 5, 780.

Micheal, S., Ayub, H., Islam, F., Siddiqui, S.N., Khan, W.A., Akhtar, F., Qamar, R., Khan, M.I., and den Hollander, A.I. (2015a). Variants in the ASB10 Gene Are Associated with Primary Open Angle Glaucoma. PloS one 10, e0145005. 
Micheal, S., Ayub, H., Zafar, S.N., Bakker, B., Ali, M., Akhtar, F., Islam, F., Khan, M.I., Qamar, R., and Hollander, A.I. (2015b). Identification of novel CYP1B1 gene mutations in patients with primary congenital and primary open-angle glaucoma. Clinical \& experimental ophthalmology 43, 31-39.

Monemi, S., Spaeth, G., DaSilva, A., Popinchalk, S., Ilitchev, E., Liebmann, J., Ritch, R., Héon, E., Crick, R.P., and Child, A. (2005). Identification of a novel adult-onset primary open-angle glaucoma (POAG) gene on 5q22. 1. Human molecular genetics 14, 725-733.

Nemesure, B., He, Q., Mendell, N., Wu, S.Y., Hejtmancik, J.F., Hennis, A., and Leske, M.C. (2001). Inheritance of open-angle glaucoma in the Barbados family study. American journal of medical genetics 103, 36-43.

Neufeld, A.H. (2004). Pharmacologic neuroprotection with an inhibitor of nitric oxide synthase for the treatment of glaucoma. Brain research bulletin 62, 455-459.

Osborne, N.N., Wood, J.P., Cupido, A., Melena, J., and Chidlow, G. (2002). Topical flunarizine reduces $I O P$ and protects the retina against ischemia-excitotoxicity. Investigative ophthalmology \& visual science 43, 1456-1464.

Pascolini, D., Mariotti, S., Pokharel, G., Pararajasegaram, R., Etya'ale, D., Négrel, A.-D., and Resnikoff, S. (2009). 2002 global update of available data on visual impairment: a compilation of population-based prevalence studies. Ophthalmic epidemiology.

Quigley, H.A. (1996). Number of people with glaucoma worldwide. British Journal of Ophthalmology 80, 389-393.

Quigley, H.A., and Broman, A.T. (2006). The number of people with glaucoma worldwide in 2010 and 2020. British journal of ophthalmology 90, 262-267.

Quigley, H.A., Congdon, N.G., and Friedman, D.S. (2001). Glaucoma in China (and worldwide): changes in established thinking will decrease preventable blindness. British Journal of Ophthalmology 85, 1271-1272.

Rauf, B., Irum, B., Kabir, F., Firasat, S., Naeem, M.A., Khan, S.N., Husnain, T., Riazuddin, S., Akram, J., and Riazuddin, S.A. (2016). A spectrum of CYP1B1 mutations associated with primary congenital glaucoma in families of Pakistani descent. Human Genome Variation 3, 16021.

Resnikoff, S., Pascolini, D., Etya'ale, D., Kocur, I., Pararajasegaram, R., Pokharel, G.P., and Mariotti, S.P. (2004). Global data on visual impairment in the year 2002. Bulletin of the world health organization 82, 844-851.

Salmon, J.F. (1999). Predisposing factors for chronic angle-closure glaucoma. Progress in retinal and eye research 18, 121-132.

Sarfarazi, M. (1997). Recent advances in molecular genetics of glaucomas. Human molecular genetics 6, 1667-1677.

Sarfarazi, M., Akarsu, N.A., Hossain, A., Turacli, E.M., Aktan, G.S., Barsoum-Homsy, M., Chevrette, L., and Sayli, S.B. (1995). Assignment of a locus (GLC3A) for primary congenital glaucoma (Buphthalmos) to 2p21 and evidence for genetic heterogeneity. Genomics 30, 171-177.

Sarfarazi, M., Stoilov, I., and Schenkman, J.B. (2003). Genetics and biochemistry of primary congenital glaucoma. Ophthalmology Clinics 16, 543-554.

Schwartz, K., and Budenz, D. (2004). Current management of glaucoma. Current opinion in ophthalmology 15, 119-126. 
Sohn, S., Im, J.-E., Kim, T.E., and Kee, C. (2013). Effect of heat shock protein 72 expression on etoposide-induced cell death of rat retinal ganglion cells. Korean Journal of Ophthalmology 27, 48-51.

Stoilov, I., Akarsu, A.N., and Sarfarazi, M. (1997). Identification of three different truncating mutations in cytochrome P4501B1 (CYP1B1) as the principal cause of primary congenital glaucoma (Buphthalmos) in families linked to the GLC3A locus on chromosome 2p21. Human molecular genetics 6, 641-647.

Stoilov, I.R., Costa, V.P., Vasconcellos, J.P., Melo, M.B., Betinjane, A.J., Carani, J.C., Oltrogge, E.V., and Sarfarazi, M. (2002). Molecular genetics of primary congenital glaucoma in Brazil. Investigative ophthalmology \& visual science 43, 1820-1827.

Stone, E.M., Fingert, J.H., Alward, W.L., Nguyen, T.D., Polansky, J.R., Sunden, S.L., Nishimura, D., Clark, A.F., Nystuen, A., and Nichols, B.E. (1997). Identification of a gene that causes primary open angle glaucoma. Science 275, 668-670.

Thanos, S., and Naskar, R. (2004). Correlation between retinal ganglion cell death and chronically developing inherited glaucoma in a new rat mutant. Experimental eye research 79, 119-129.

Waryah, A.M., Narsani, A.K., Sheikh, S.A., Shaikh, H., and Shahani, M.Y. (2013). The novel heterozygous Thr377Arg MYOC mutation causes severe Juvenile Open Angle Glaucoma in a large Pakistani family. Gene 528, 356-359.

Wiggs, J.L. (2007). Genetic etiologies of glaucoma. Archives of ophthalmology 125, 30-37.

Woodward, D.F., and Gil, D.W. (2004). The inflow and outflow of anti-glaucoma drugs. Trends in pharmacological sciences 25, 238-241.

Zhong, H., Li, J., Li, C., Wei, T., Cha, X., Cai, N., Luo, T., Yu, M., and Yuan, Y. (2012). The Prevalence of Glaucoma in Adult Rural Chinese Populations of the Bai Nationality in Dali: The Yunnan Minority Eye StudyPrevalence of Glaucoma in Adult Chinese Bai Nationality. Investigative ophthalmology \& visual science 53, 3221-3225. 